Article

\title{
Esters of Glucose-2-Phosphate: Occurrence and Chemistry
}

\author{
Qiang Zhang, Si-Zhe Li, Mohammed Ahmar, Laurent Soulère and Yves Queneau * (B) \\ Univ Lyon, Université Claude Bernard Lyon 1, CNRS, INSA Lyon, CPE Lyon, ICBMS, UMR 5246, Bât. E. Lederer, \\ 1 rue Victor Grignard, F-69622 Villeurbanne, France; qiang.zhang@insa-lyon.fr (Q.Z.); \\ s.li@lic.leidenuniv.nl (S.-Z.L.); mohammed.ahmar@univ-lyon1.fr (M.A.); laurent.soulere@insa-lyon.fr (L.S.) \\ * Correspondence: yves.queneau@insa-lyon.fr; Tel.: +33-(0)-4-81-92-99-00
}

Academic Editor: László Somsák

Received: 26 May 2020; Accepted: 17 June 2020; Published: 19 June 2020

check for updates

\begin{abstract}
Phosphodiesters of glucose-2-phosphate (G2P) are found only in few natural compounds such as agrocinopine $\mathrm{D}$ and agrocin 84 . Agrocinopine D is a G2P phosphodiester produced by plants infected by Agrobacterium fabrum C58 and recognized by the bacterial periplasmic binding protein AccA for being transported into the bacteria before cleavage by the phosphodiesterase AccF, releasing G2P, which promotes virulence by binding the repressor protein AccR. The G2P amide agrocin 84 is a natural antibiotic produced by the non-pathogenic Agrobacterium radiobacter K84 strain used as a biocontrol agent by competing with Agrobacterium fabrum C58. G2P esters are also found in irregular glycogen structures. The rare glucopyranosyl-2-phophoryl moiety found in agrocin 84 is the key structural signature enabling its action as a natural antibiotic. Likewise, G2P and G2P esters can also dupe the Agrobacterium agrocinopine catabolism cascade. Such observations illustrate the importance of G2P esters on which we have recently focused our interest. After a brief review of the reported phosphorylation coupling methods and the choice of carbohydrate building blocks used in G2P chemistry, a flexible access to glucose-2-phosphate esters using the phosphoramidite route is proposed.
\end{abstract}

Keywords: agrocinopine; glucose-2-phosphate; phosphodiesters; agrocin 84; Agrobacterium fabrum

\section{Introduction}

Glucose-2-phosphate esters are rare structures, found in only a few natural compounds, among which agrocinopine D and agrocin 84 . Agrocinopines are a family of opines, which are plasmid-coded enzyme products produced by pathogenic bacteria of the genus of Agrobacterium. Agrobacterium fabrum are Gram negative bacteria which cause tumors in plants, causing diseases such as crown gall, hairy root, and cane gall. In the process of infection by Agrobacterium fabrum C58, agrocinopines serve as nutrients and as relays in the production of quorum-sensing autoinducers. These latter subsequently control the expression of virulence genes and bacterial population $[1,2]$. Four agrocinopines $(A, B, C$ and D, Figure 1) have been identified and are specific to A. fabrum strains C58 and strains Bo542 [2]. They differ in structure by being either glucose or arabinose phosphodiesters, connected with sucrose, glucose or fructose moieties (Figure 1). In Agrobacterium fabrum, the agrocinopine catabolism cascade involves several proteins notably AccA and AccF which are responsible for the import of agrocinopine back into the bacteria, and for the cleavage of its phosphodiester linkage, respectively.

A phosphoramidate analog of agrocinopines is the natural antibiotic agrocin 84 produced by Agrobacterium radiobacter $\mathrm{K} 84$ which is a non-pathogenic bacterial strain competing with Agrobacterium fabrum C58. If agrocin 84 enters into Agrobacterium fabrum C58 cells, its phosphodiester linkage is cleaved by AccF, releasing the toxic TM84 fragment acting as a leucine synthase inhibitor resulting in bacterial death [3]. Agrobacterium radiobacter can thus be used as a biocontrol agent. 

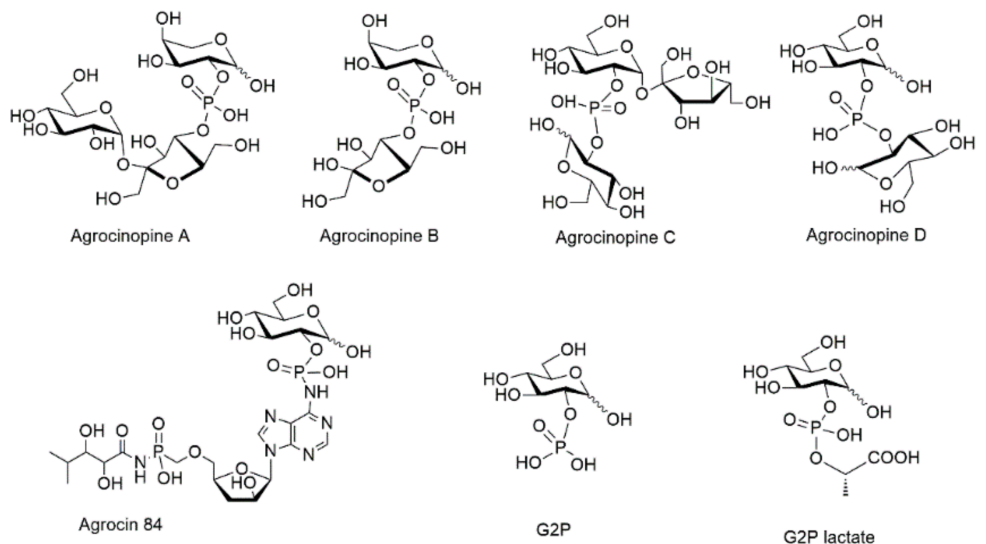

Figure 1. Structures of agrocinopines A, B, C and D, D-glucose-2-phosphate (G2P) and its esters G2P lactate, its amide agrocin 84 .

The carbohydrate signature of the agrocinopines is therefore the key for the three protein-carbohydrate recognition events, first through specific recognition by the periplasmic binding proteins AccA. Then, once imported, it is recognized and hydrolyzed by the phosphodiesterase AccF. Finally, the resulting fragment binds with the repressor protein AccR responsible for virulence activation through the activation of quorum sensing signals synthesis [3].

If agrocin 84 can act as a natural antibiotic, it is because it shares the rare pyranose-2-phosphate chemical signature with agrocinopines. Agrocin 84 structure was first proposed to be a glucofuranose 1-O-phosphate though not ruling out other connections [4,5]. Its structure was fully identified as a glucopyranosyl-2-phosphoryl derivative after X-ray crystallography diffraction studies of its complex with AccA [6]. The ability of G2P esters to dupe the acc cascade of Agrobacterium fabrum was also confirmed using the G2P lactic acid ester (G2LP) found to be the first non-natural G2P ester to mimic the role of natural agrocinopine A [7].

Considering the importance of the G2P motif in plant pathogens, and their originality in biology compared to glucose-1-phosphates (G1P) or glucose-6-phosphates (G6P), we have further focused our attention on their chemical synthesis. Below we briefly review the chemistry of G2P and its esters, discussing the phosphorylation methods and possible carbohydrate building blocks, before applying an updated sequence to the synthesis of a short series of derivatives.

\section{Results}

Although phosphate esters are very frequent in biologically relevant carbohydrates [8], there are only a handful of G2P phosphodiesters reported in the literature. Apart from the family of agrocinopines and analogues mentioned above, the G2P motif was only found in glycogen, together with G3P and the more common G6P. Glycogen-bound phosphate influences glycogen architecture with different branching and chain length. Even if glucose phosphates are structurally similar, G1P and G6P are involved in the processes of glycogen degradation and synthesis, respectively. Oppositely, G2P or G3P residues cannot be confirmed by biochemical enzymatic assays as there is no known enzyme with specific activity towards these two phosphates [9-11]. Actually, glucose-2-phsophate itself was used for studying phosphate stability or hydrolysis rates $[8,12,13]$, or for identification of the hydrolyzed monomeric forms of glycogen to understand the metabolism of the phosphate in this biopolymer $[9,14]$. The quite uncommon D-glucose-2-phosphate (G2P), which refer to phosphate covalently bonded glucose hydroxyl at C-2 position, was firstly and unequivocally synthesized by Farrar [15] in 1949. The hydrolysis of the cyclic glucose-1,2-phosphate (GCP) can afford a mixture of G2P and G1P. During hydrolysis, G2P esters exhibit higher stability versus G1P [12,15]. 


\subsection{Phosphorylation and Coupling Methods}

In the synthesis of G2P and its phosphodiesters, a first issue is the choice between various methods for installing the phosphorus on the glucose residue and further connecting the other moiety. Several methods have been developed in the field of carbohydrates and oligonucleotide [16], glycoside and peptide synthesis, but only few have been applied to the case of G2P and its esters. Farrar's first unequivocal G2P synthesis [15] involved diphenyl chlorophosphate (3 days in pyridine) as phosphorylation reagent (Scheme 1). The method used by Lindberg and Oscarson [17] for reaching an agrocinopine $C$ precursor was the condensation of sucrose derivative and hydrogenphosphate in pyridine, while for reaching an agrocinopine $\mathrm{D}$ precursor, they performed the condensation of glucose derivative with a phosphonic acid in pyridine, activated by an acyl chloride $[18,19]$. The use of excess glucose building block was needed to make the reaction complete. The purification of the highly polar phosphonate diesters intermediates (in their salt form) requires consecutive ion exchange columns.

1) previous work by Farrar (1949)

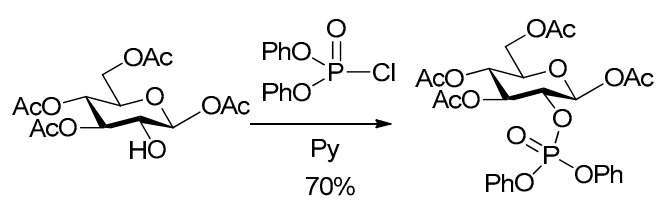

2) previous work by Lindberg and Oscarson (1993)
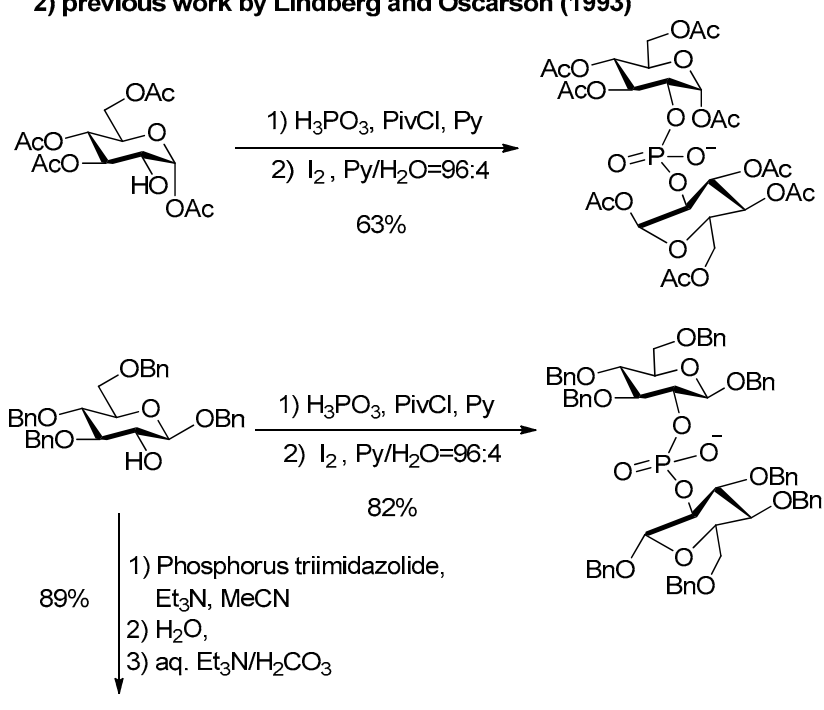

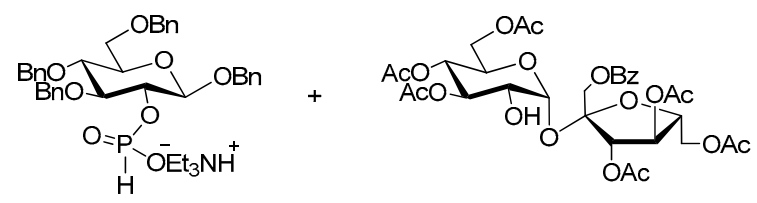

3) previous work by our lab $(2015,2019)$

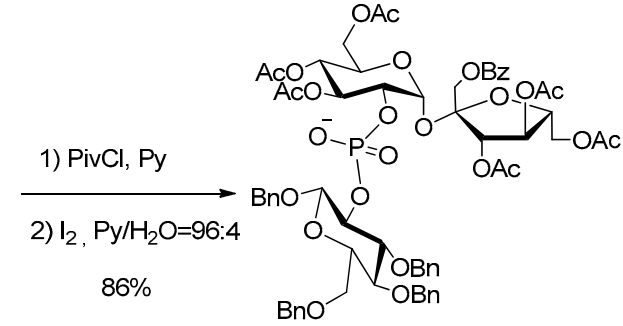



Scheme 1. Previous synthesis of the precursors of agrocinopine C and D, G2P and G2LP. 
In the chemistry of agrocinopines A and B [20], which involve an arabinose building block instead of a glucose one in agrocinopines C and D, Thiem and coworkers used trichloroethyl phosphorodichloridate with 1,2,4-triazole in pyridine as coupling reagent. More recently, our team has used the convenient phosphoramidite strategy for constructing the phosphodiester both in the arabinose and glucose series [6,7]. This method combines easiness and flexibility for a diversity-oriented strategy towards a variety of agrocinopine analogs from various sugars and alcohols.

\subsection{Building Blocks}

The overall efficiency of these syntheses relies also on the availability of the carbohydrate building blocks possessing the appropriate partial protection required for selective phosphorylation at C-2. Several 2-OH free glucoses have been reported in literature, most of them with benzyl and/or acetyl groups at $O-1,3,4$ and 6 . In the synthesis of G2P, Farrar [15] used 1,3,4,6-tetraacetyl- $\beta$-glucose, which was prepared following Hardegger and Pascual procedure [21] by reaction of 3,4,6-tri-O-acetyl-1,2-anhydro- $\alpha$-D-glucopyranose with HOAc (Scheme $2 \mathrm{a}$ ). The easy purification by crystallization makes this sequence quite efficient. Alternatively, the hydrolysis of halogenated acetoglucose can also lead to tetraacetyl glucose with only 2-OH free [22-24] (Scheme 2b,c).

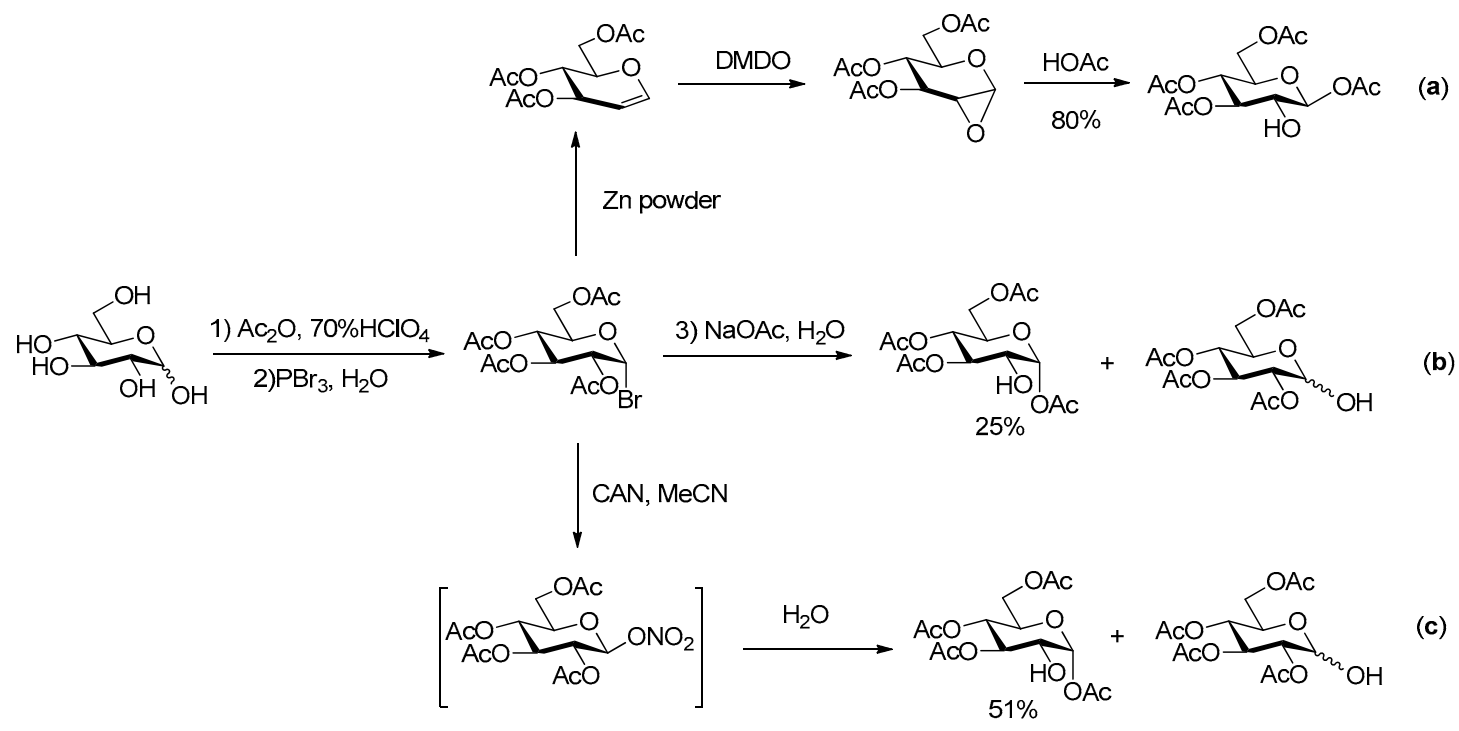

Scheme 2. Previous synthetic routes for acetylated glucose with 2-OH free [21-24].

However, considering the risk of acetyl group migrations, leading to undesired mixtures of regioisomers in the course of the phosphorylation step, less labile protecting groups should be preferred. For example, one of us reported an allyl glucoside with only the 2-OH free as other positions are protected as a 4,6-O-benzylidene and a 3-O-allyl ether [25]. Even more appropriate is the use of benzyl ethers, both at the anomeric and other positions, in order to keep an easy final and practical deprotection procedure. Therefore, benzyl 3,4,6-tri-O-benzyl-D-glucopyranoside appears as the ideal glucose precursor. In the only previously reported synthesis of agrocinopine D, Lindberg and Oscarson [17] used this building block as its $\beta$ anomer. They relied on a 5 steps synthesis starting from tetra- $O$-acetyl- $\alpha$-D-glucopyranosyl bromide, formation of the 1,2-orthoester, Zemplén deacetylation followed by Williamson etherification using benzyl bromide to the tri-O-benzyl orthoester, then $\mathrm{HgBr}_{2}$-mediated glycosylation with benzyl alcohol and deacetylation to tetrabenzyl derivative 1 (Scheme 3a). The $\alpha$ anomer benzyl 3,4,6-tri-O-benzyl- $\alpha$-D-glucopyranoside 2 can be made from endo-type 1,2-O-benzylidene acetal [26] or using the elegant reductive selective 2-O-debenzylation promoted by triisobutyl aluminum (TIBAL) [27] of perbenzyl glucose [6,7] (Scheme 3b,c). However, this latter debenzylation step only proceeds on the $\alpha$ anomer, limiting significantly the overall yield 
when mixtures of anomers are used as substrate as all the $\beta$ anomer remains untransformed. The shortest and most efficient sequence appears to be based on the Lewis acid-catalyzed opening reaction of the readily available 1,2-anhydro- $\alpha$-D-glucopyranose [28,29] leading to 1 in high yield within only 2 steps from the commercially available benzylated glucal (Scheme 3d). Based on this survey, this latter access to 1 was used in the following work towards G2P and G2P esters.

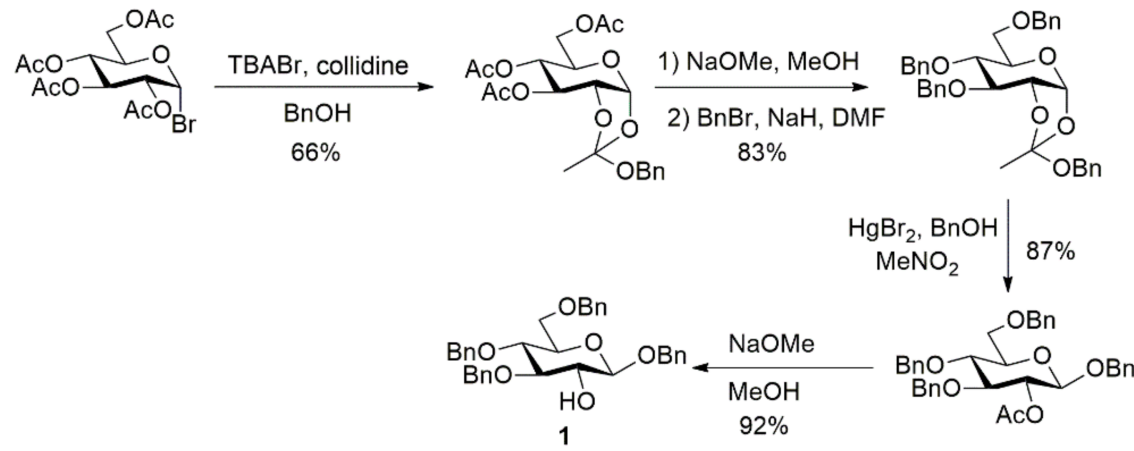

b

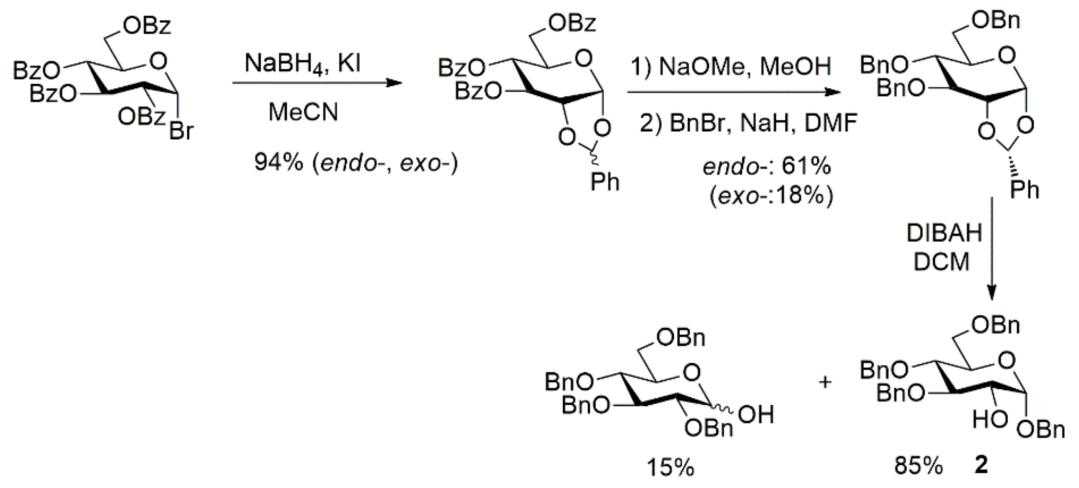

C

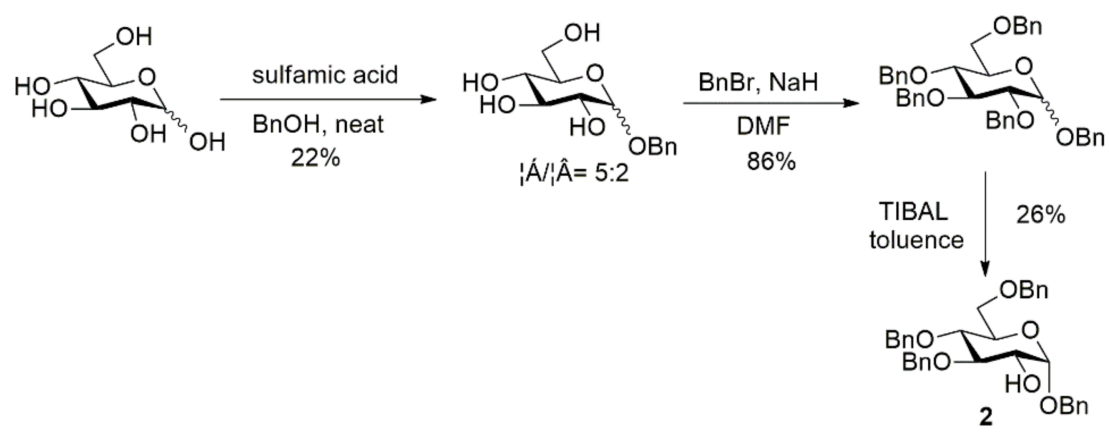

d

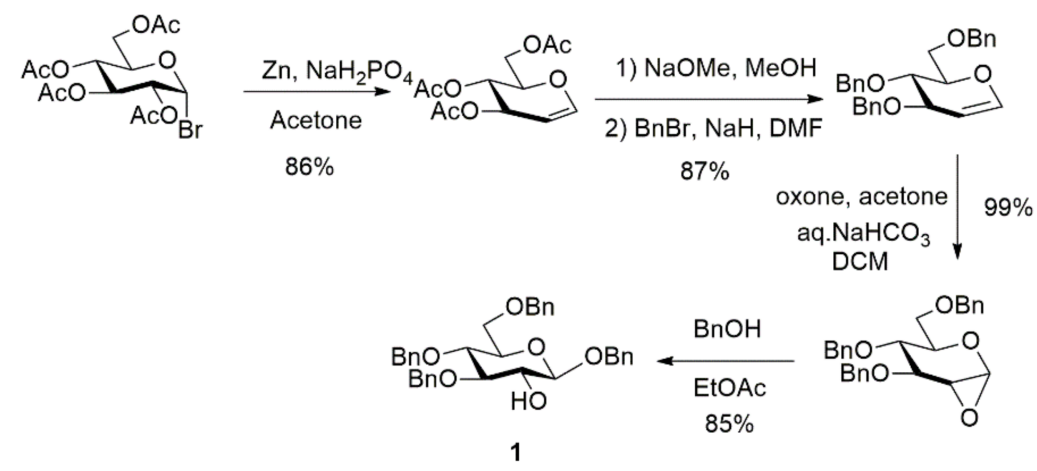

Scheme 3. Various accesses to tetrabenzylated glucose with 2-OH free [26-29]. 


\subsection{Alternative Flexible Access to G2P and Esters}

Aiming at proposing a more general and flexible access able to lead to G2P or its esters, we thus applied the phosphoramidite coupling strategy to the 3,4,6-tri-O-benzyl- $\beta$-D-glucopyranoside building block 1 . Reaction with benzyloxy bis(diisopropylamino)phosphine gave selectively the monoaminated phosphoramidite 3 in $81 \%$ yield in the presence of diisopropylammonium tetrazolide as mild and hindered base preventing double diisopropylamino displacement [30]. The phosphoramidite 3 was then used in coupling reactions with different alcohols, as shown in Table 1.

Table 1. Synthesis of the precursors of glucose-2-phosphate and derivatives.

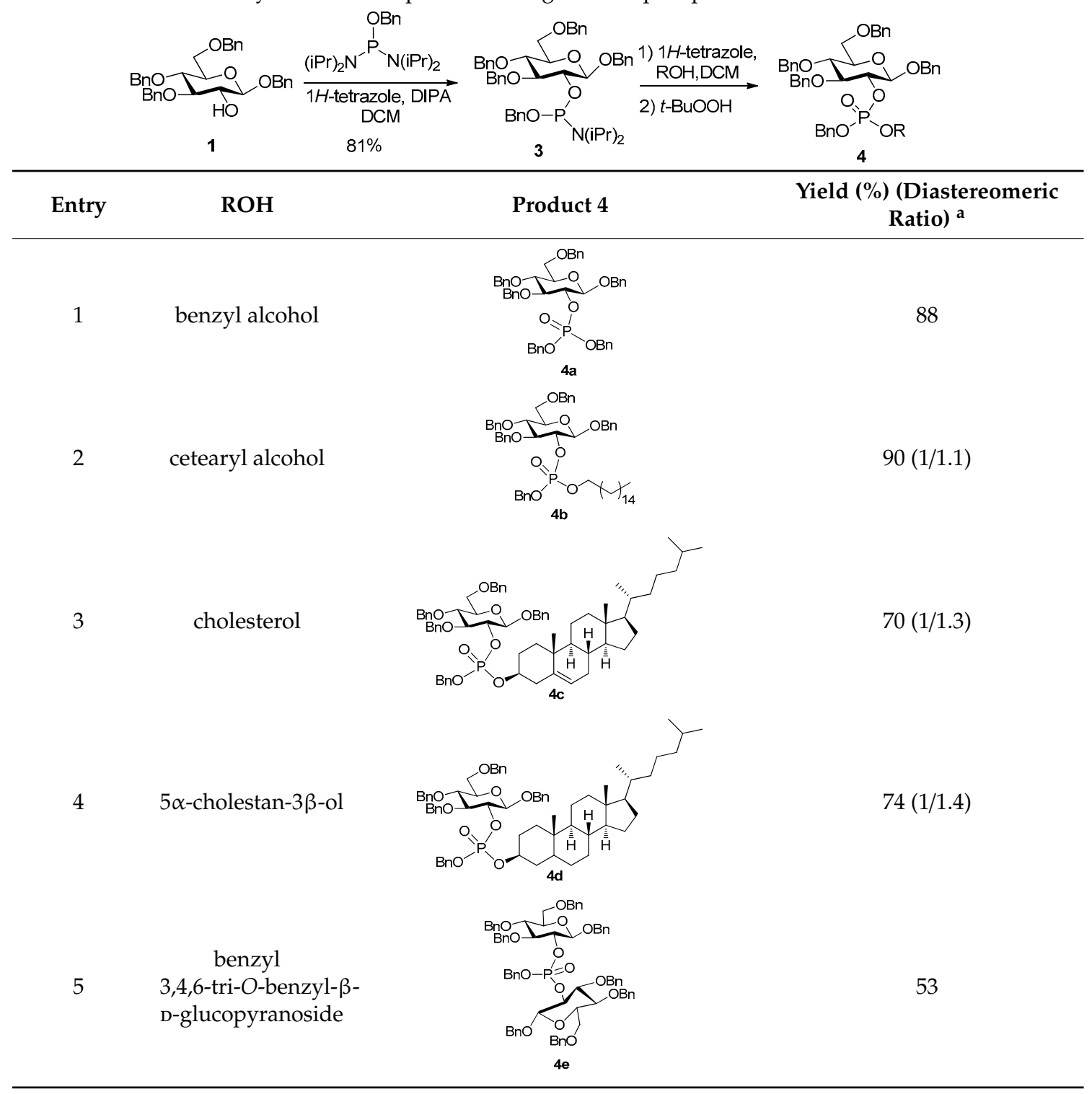

a. Measured by ${ }^{31} \mathrm{P}-\mathrm{NMR}$.

The conversion of phosphoramidite 3 into phosphotriesters 4 was conducted in a two-step one-pot procedure, involving firstly the reaction with the alcohol leading to an intermediate phosphite, and secondly the oxidation of the phosphite to the phosphate using tert-BuOOH. The reaction with benzyl alcohol gave the fully protected G2P $4 \mathrm{a}$ in $88 \%$ yield. The reaction was also conducted with a short scope of primary or secondary alcohols including cetearyl alcohol, cholesterol, $5 \alpha$-cholestan-3 $\beta$-ol (dihydrocholesterol) and glucoside 1 having only 2-OH available. All gave fair to good yields, with primary alcohols showing logically higher reactivity, while secondary suffer from steric hindrance. 
Owing to the chiral center of the phosphorus atom, phosphates $4 \mathrm{~b}, \mathbf{4 c}$ and $4 \mathrm{~d}$ were obtained as a mixture of the two diastereoisomers in nearly 1:1 ratio determined by ${ }^{31} \mathrm{P}-\mathrm{NMR}$ spectra.

Considering the interest of agrocinopine $\mathrm{D}$, and its symmetrical structure, we investigated a one-pot access to the protected phosphodiester $4 \mathbf{e}$ from the glucose building block $\mathbf{1}$ in which the intermediate bis-glucosyl phosphite was not isolated (Scheme 4). This step was optimized with respect to the stoichiometry between substrate 1, phosphoramidite and tetrazole. When the reaction was carried out with only 1.0 equivalent phosphoramidite (compared to the 2.0 equivalents of substrate 1), low conversion of substrate 1 was observed. Increasing the amount of phosphoramidite to 2.0 equivalents led mainly to the formation of monoaminated phosphoramidite 3 . The most favorable conditions were found to be 1.2 equivalents of phosphoramidite and 3 equivalents of $1 \mathrm{H}$-tetrazole.

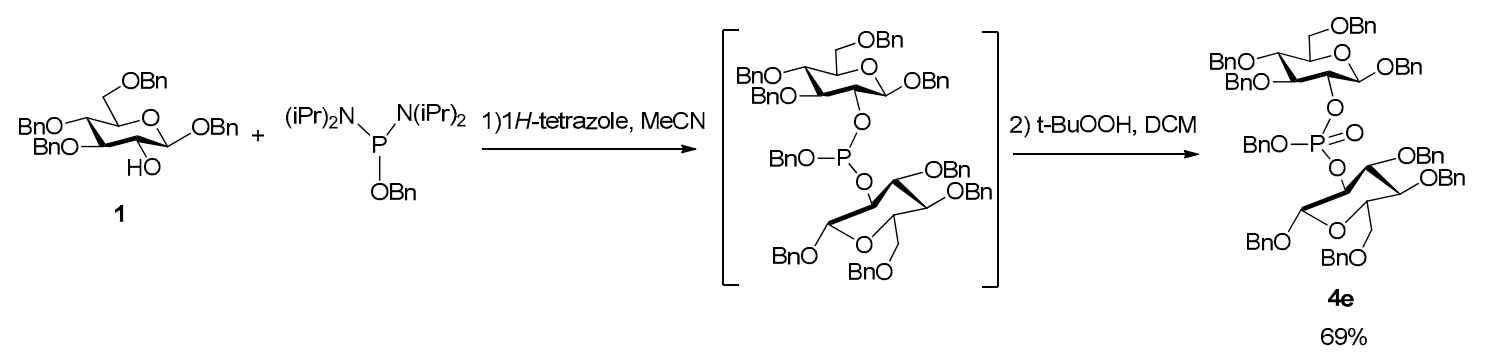

Scheme 4. Synthesis of the precursor of agrocinopine D in one-pot.

The fully deprotected targets G2P (5a) and agrocinopine D (5b) were obtained after palladium-catalyzed hydrogenolysis from compounds $4 \mathbf{a}$ and $4 \mathbf{e}$ respectively, using $1 \mathrm{~atm} \mathrm{H}_{2}$ and $\mathrm{Pd} / \mathrm{C}$ in methanol (Scheme 5). G2P 5a was obtained in high yield and purity after debenzylation in ethyl acetate. Agrocinopine D $\mathbf{5 b}$ was obtained in $78 \%$ yield as its ammonium salt after ion exchange chromatography on a DEAE-Sephadex column. Both compounds exhibited identical data as compared to literature $[6,17]$.

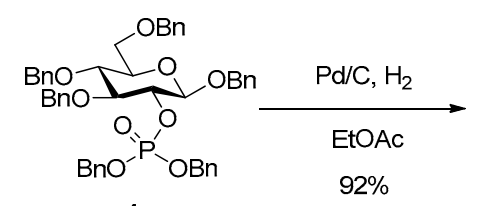

$4 a$

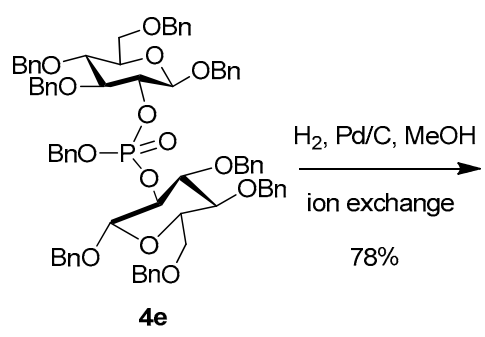

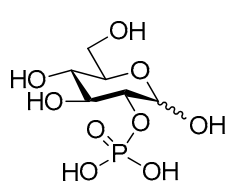

G2P $5 \mathbf{a}$

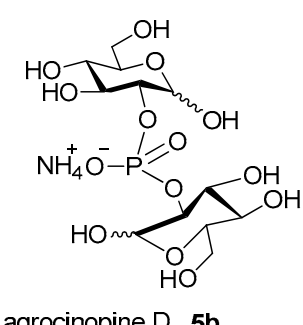

agrocinopine $D \mathbf{5 b}$

Scheme 5. Deprotection of the phosphate precursors.

\section{Materials and Methods}

\subsection{General Methods}

All commercial reagents and solvents were used without further purification. Analytical thin layer chromatography was performed on aluminum-backed plates coated with Macherey-Nagel Kieselgel 60 XtraSIL G/UV254. Macherey-Nagel Kieselgel $60 \mathrm{M}$ silica was used for flash chromatography. Synthetic products were visualized under UV light (at $254 \mathrm{~nm}$ ) or stained using concentrated sulfuric acid. NMR spectra were recorded on a Bruker $300 \mathrm{MHz}$ or a Bruker $500 \mathrm{MHz}$ spectrometer. Chemical shifts (ppm) 
were reported relative to residual solvent signals. Multiplicities are abbreviated as follows: s, singlet; $\mathrm{d}$, doublet; $\mathrm{t}$, triplet; $\mathrm{m}$, multiplet. Coupling constants were measured in Hertz (Hz). High-resolution mass spectra (HRMS) were performed by a Finnigan Mat 151xL mass spectrometer using electrospray (see supplementary materials).

3.2. Synthesis of benzyl 3,4,6-tri-O-benzyl-2-O-[benzyloxy(diisopropylamino)phosphanyl]- $\beta$ - $D$ glucopyranoside (or benzyl ((2R,3R,4S,5R,6R)-2,4,5-tris(benzyloxy)-6-((benzyloxy)methyl)tetrahydro$2 \mathrm{H}$-pyran-3-yl) diisopropylphosphoramidite) 3

Benzyl 3,4,6-tri-O-benzyl- $\beta$-D-glucopyranoside (1) was synthesized from commercially available 3,4,6-tri-O-benzyl-D-glucal as previously reported [26,27]. After recrystallization from ethanol, the resulting product 1 as white solid was subjected to the next step. To a solution of diisopropylammonium tetrazolide salt, prepared by mixing tetrazole $(1.0 \mathrm{eq}, 4.2 \mathrm{~mL}$ of a $0.45 \mathrm{M}$ solution in MeCN) with diisopropylamine $(1.2 \mathrm{eq}, 0.33 \mathrm{~mL})$ and benzyloxy bis(diisopropylamino)phosphine $(0.96 \mathrm{~g}, 2.7 \mathrm{mmol}$, 1.5 eq.) in $10 \mathrm{~mL}$ DCM, was added benzyl 3,4,6-tri-O-benzyl- $\beta$-D-glucopyranoside $(\mathbf{1}, 1 \mathrm{~g}, 1.8 \mathrm{mmol})$, which was dissolved in $10 \mathrm{~mL} \mathrm{DCM}$ at $0{ }^{\circ} \mathrm{C}$. Then the mixture was stirred overnight at room temperature. The reaction was monitored by TLC (EtOAc-pentane 1:9 with $1 \% \mathrm{Et}_{3} \mathrm{~N}$ as eluent. When the starting material was consumed, the solid salt was filtered. The organic phase was collected, concentrated and purified by silica gel chromatography (EtOAc-pentane 1:9 with $1 \% \mathrm{Et}_{3} \mathrm{~N}$ ) to give $1.2 \mathrm{~g}$ of the desired product (yield 81\%). Rf = 0.56. ${ }^{1} \mathrm{H}-\mathrm{NMR}\left(\mathrm{CDCl}_{3}, 500 \mathrm{MHz}\right): \delta(\mathrm{ppm}) 7.38-7.09(\mathrm{~m}, 23 \mathrm{H}, \mathrm{Ph}), 7.07-7.00$ (m, 2H, Ph), 4.93 (m, 1H, CHHPh), $4.84(\mathrm{~m}, 1 \mathrm{H}, \mathrm{CHHPh}), 4.74-4.43\left(\mathrm{~m}, 8 \mathrm{H}, 4 \times \mathrm{CH}_{2} \mathrm{Ph}\right), 4.40(\mathrm{~d}, \mathrm{~J}=$ $7.5 \mathrm{~Hz}, 1 \mathrm{H}, \mathrm{H}-1), 3.84$ (m, 1H, H-2), 3.66-3.51 (m, 6H, H6a, H6b, H-4, H-3, 2×CH), 3.42 (m, 1H, H-5), 1.07-0.96 (m, 12H, 4×CH$) ;{ }^{13} \mathrm{C}-\mathrm{NMR}\left(126 \mathrm{MHz}, \mathrm{CDCl}_{3}\right) \delta(\mathrm{ppm}) 139.9(\mathrm{C}-\mathrm{Ph}), 139.6(\mathrm{C}-\mathrm{Ph}), 138.8$ (C-Ph), 138.3 (C-Ph), 137.7 (C-Ph), $128.4(\mathrm{Ph}), 128.4(\mathrm{Ph}), 128.4(\mathrm{Ph}), 128.3(\mathrm{Ph}), 128.2(\mathrm{Ph}), 128.2(\mathrm{Ph})$, $128.1(\mathrm{Ph}), 128.0(\mathrm{Ph}), 128.0(\mathrm{Ph}), 128.0(\mathrm{Ph}), 127.9(\mathrm{Ph}), 127.8(\mathrm{Ph}), 127.8(\mathrm{Ph}), 127.8(\mathrm{Ph}), 127.7(\mathrm{Ph})$, 127.7 (Ph), 127.6 (Ph), 127.6 (Ph), 127.6 (Ph), 127.4 (Ph), 127.3 (Ph), 127.2 (Ph), 127.1 (Ph), $127.0(\mathrm{Ph})$, $127.0(\mathrm{Ph}), 102.0(\mathrm{C} 1), 101.7\left(\mathrm{~d}, J_{\mathrm{C}-\mathrm{P}}=2.9 \mathrm{~Hz}, \mathrm{C1}^{\prime}\right), 85.5\left(\mathrm{~d}, J_{\mathrm{C}-\mathrm{P}}=2.8 \mathrm{~Hz}, \mathrm{C} 3\right), 85.4\left(\mathrm{C}^{\prime}\right), 78.1(\mathrm{C} 4), 76.2$ $\left(\mathrm{d}, J_{\mathrm{C}-\mathrm{P}}=10.9 \mathrm{~Hz}, \mathrm{C} 2^{\prime}\right), 75.9\left(\mathrm{~d}, \mathrm{~J}_{\mathrm{C}-\mathrm{P}}=5.2 \mathrm{~Hz}, \mathrm{C} 2\right), 75.2\left(\mathrm{CH}_{2} \mathrm{Ph}\right), 75.0\left(\mathrm{C} 5, \mathrm{C}^{\prime}\right), 74.9\left(\mathrm{CH}_{2} \mathrm{Ph}\right), 73.5$ $\left(\mathrm{CH}_{2} \mathrm{Ph}\right), 70.8\left(\mathrm{CH}_{2} \mathrm{Ph}\right), 69.2\left(\mathrm{C6}, \mathrm{C6}^{\prime}\right), 65.5\left(\mathrm{CH}_{2} \mathrm{Ph}\right), 43.1(\mathrm{CH}), 43.0(\mathrm{CH}), 24.7\left(\mathrm{CH}_{3}\right), 24.6\left(\mathrm{CH}_{3}\right), 24.6$ $\left(\mathrm{CH}_{3}\right), 24.5\left(\mathrm{CH}_{3}\right) .{ }^{31} \mathrm{P}-\mathrm{NMR}\left(\mathrm{CDCl}_{3}, 122 \mathrm{MHz}\right): \delta$ (ppm) 151.44, 150.23 (ratio 1/1.3). HR-MS (ESI): $\mathrm{C}_{47} \mathrm{H}_{59} \mathrm{NO}_{8} \mathrm{P}\left[\mathrm{M}+\mathrm{H}_{3} \mathrm{O}\right]^{+}$requires: 796.3973; found: 796.3976 .

\subsection{General Procedure for the two-step Synthesis of Phosphotriesters $\mathbf{4 a - e}$}

To a solution of phosphoramidite $3(155 \mathrm{mg}, 0.2 \mathrm{mmol})$ in $2 \mathrm{~mL}$ DCM was added corresponding alcohol $(0.2 \mathrm{mmol})$ dissolved in $1 \mathrm{~mL}$ DCM, $1 H$-tetrazole $(4.5 \mathrm{~mL}$ of a $0.45 \mathrm{M}$ solution in MeCN, 0.2 $\mathrm{mmol})$ at $\mathrm{rt}$. Then the mixture was stirred for $5 \mathrm{~h}$ at $\mathrm{rt}$. After completion of the reaction, $t$ - $\mathrm{BuOOH}(43$ $\mu \mathrm{L}$ of a $5.6 \mathrm{M}$ solution in decane, $0.24 \mathrm{mmol}$ ) was added. After $1 \mathrm{~h}$, the white solid was filtered. The organic phase was collected, concentrated and purified by silica gel chromatography.

3.3.1. Benzyl 3,4,6-tri-O-benzyl-2-O-dibenzylphosphonato- $\beta$-D-glucopyranoside [or dibenzyl ((2R,3R,4S,5R,6R)-2,4,5-tris(benzyloxy)-6-((benzyloxy)methyl)tetrahydro-2H-pyran-3-yl) phosphate] 4 a

From benzyl alcohol $(20 \mu \mathrm{L})$ following general procedure, TLC monitoring using EtOAc-pentane 1:3 as eluent, flash chromatography of the crude product (1:3 EtOAc-pentane) afforded 4a (yield 88\%) as a white solid. $\mathrm{Rf}=0.43 .{ }^{1} \mathrm{H}-\mathrm{NMR}\left(\mathrm{CDCl}_{3}, 500 \mathrm{MHz}\right): \delta(\mathrm{ppm}) 7.31(\mathrm{~m}, 8 \mathrm{H}, \mathrm{Ph}), 7.25-7.13(\mathrm{~m}$, 16H, Ph), 7.12-7.01 (m, 6H, Ph), 4.93-4.85 (m, 4H, 2×CH2 Ph), 4.82 (m, 1H, CHHPh), 4.79-4.68 (m, 3H, $\left.\mathrm{CHHPh}, \mathrm{CH}_{2} \mathrm{Ph}\right), 4.61-4.55\left(\mathrm{~m}, 2 \mathrm{H}, \mathrm{CH}_{2} \mathrm{Ph}\right), 4.51(\mathrm{~d}, \mathrm{~J}=10 \mathrm{~Hz}, 1 \mathrm{H}, \mathrm{H1}), 4.50-4.47\left(\mathrm{~m}, 2 \mathrm{H}, \mathrm{CH} \mathrm{H}_{2} \mathrm{Ph}\right)$, 4.45-4.39 (m, 1H, H2), 3.70-3.62 (m, 4H, H6a, H6b, H3, H4), 3.45 (m, 1H, H5); ${ }^{13} \mathrm{C}-\mathrm{NMR}\left(\mathrm{CDCl}_{3}, 126\right.$ $\mathrm{MHz}): \delta$ (ppm) 138.3, 138.1, 137.9, 136.9, 136.2, 136.1, 128.4, 128.4, 128.4, 128.4, 128.3, 128.2, 128.2, 128.0, $127.9,127.8,127.8,127.7,127.7,127.7,127.6,127.5,100.1\left(\mathrm{~d}, J_{\mathrm{C}-\mathrm{P}}=3.7 \mathrm{~Hz}, \mathrm{C} 1\right), 83.7\left(\mathrm{~d}, J_{\mathrm{C}-\mathrm{P}}=4.0 \mathrm{~Hz}\right.$, C3), $79.1\left(\mathrm{~d}, J_{\mathrm{C}-\mathrm{P}}=6.9 \mathrm{~Hz}, \mathrm{C} 2\right), 77.8(\mathrm{C} 4), 75.2(\mathrm{C} 5), 75.1\left(\mathrm{OCH}_{2} \mathrm{Ph}\right), 75.0\left(\mathrm{OCH}_{2} \mathrm{Ph}\right), 73.6(\mathrm{OCH} \mathrm{Ph})$, 
$70.8\left(\mathrm{OCH}_{2} \mathrm{Ph}\right), 69.2\left(\mathrm{~d}, J_{\mathrm{C}-\mathrm{P}}=5.2 \mathrm{~Hz}, \mathrm{OCH}_{2} \mathrm{Ph}\right), 69.1\left(\mathrm{~d}, J_{\mathrm{C}-\mathrm{P}}=5.3 \mathrm{~Hz}, \mathrm{OCH}_{2} \mathrm{Ph}\right), 68.7(\mathrm{C} 6) ;{ }^{31} \mathrm{P}-\mathrm{NMR}$ $\left(\mathrm{CDCl}_{3}, 122 \mathrm{MHz}\right.$ ): $\delta(\mathrm{ppm})-1.71 .[\alpha]_{D}^{24}=-25.1\left(\mathrm{c}=0.4\right.$, acetone). $\mathrm{mp}: 83.1 \sim 83.4^{\circ} \mathrm{C}$. HR-MS (ESI): $\mathrm{C}_{48} \mathrm{H}_{49} \mathrm{NaO}_{9} \mathrm{P}[\mathrm{M}+\mathrm{Na}]^{+}$requires: 823.3006; found: 823.3006 .

3.3.2. Benzyl 3,4,6-tri-O-benzyl-2-O-[(benzyl)(hexadecyl)phosphonato]- $\beta$-D-glucopyranoside [or benzyl hexadecyl ((2R,3R,4S,5R,6R)-2,4,5-tris(benzyloxy)-6-((benzyloxy)methyl)tetrahydro- $2 \mathrm{H}$ pyran-3-yl) phosphate] $4 \mathrm{~b}$

From cetearyl alcohol (48 mg) following general procedure, TLC monitoring using EtOAc-pentane 1:3 as eluent, flash chromatography of the crude product (1:1 EtOAc-pentane) afforded $4 \mathbf{b}$ (yield $90 \%$ ) as a white solid. $\mathrm{Rf}=0.4 .{ }^{1} \mathrm{H}-\mathrm{NMR}\left(\mathrm{CDCl}_{3}, 500 \mathrm{MHz}\right): \delta(\mathrm{ppm}) 7.46-7.41(\mathrm{~m}, 1 \mathrm{H}, \mathrm{Ph}), 7.41-7.12(\mathrm{~m}$, 24H, Ph), 5.08-4.88 (m, 4H, 2× $\left.\mathrm{CH}_{2} \mathrm{Ph}\right), 4.88-4.81$ (m, 1H, CHHPh), 4.81-4.75 (m, 1H, CHHPh), 4.70-4.61 $\left(\mathrm{m}, 2 \mathrm{H}, \mathrm{CH}_{2} \mathrm{Ph}\right), 4.57(\mathrm{~d}, J=8.3 \mathrm{~Hz}, 1 \mathrm{H}, \mathrm{H1}), 4.56-4.53\left(\mathrm{~m}, 2 \mathrm{H}, \mathrm{CH}_{2} \mathrm{Ph}\right), 4.45(\mathrm{~m}, 1 \mathrm{H}, \mathrm{H} 2), 3.94-3.81(\mathrm{~m}$, 2H, $\left.\mathrm{OCH}_{2}\right), 3.79-3.68(\mathrm{~m}, 4 \mathrm{H}, \mathrm{H} 3, \mathrm{H} 4, \mathrm{H} 6 \mathrm{a}, \mathrm{H6b}), 3.51$ (m, 1H, H5), 1.51-1.37 (m, 2H, $\left.\mathrm{CH}_{2}\right), 1.28$ (m, 26H, $\left.13 \times \mathrm{CH}_{2}\right), 0.90\left(\mathrm{t}, J=6.9 \mathrm{~Hz}, 3 \mathrm{H}, \mathrm{CH}_{3}\right) ;{ }^{13} \mathrm{C}-\mathrm{NMR}\left(\mathrm{CDCl}_{3}, 126 \mathrm{MHz}\right): \delta(\mathrm{ppm}) 138.3(\mathrm{Ph}), 138.1$ (Ph), $137.9(\mathrm{Ph}), 137.0(\mathrm{Ph}), 136.3(\mathrm{Ph}), 128.6(\mathrm{Ph}), 128.5(\mathrm{Ph}), 128.4(\mathrm{Ph}), 128.4(\mathrm{Ph}), 128.4(\mathrm{Ph}), 128.3$ (Ph), $128.3(\mathrm{Ph}), 128.3(\mathrm{Ph}), 128.2(\mathrm{Ph}), 128.1(\mathrm{Ph}), 128.1(\mathrm{Ph}), 128.0(\mathrm{Ph}), 128.0(\mathrm{Ph}), 127.9(\mathrm{Ph}), 127.8$ $(\mathrm{Ph}), 127.8(\mathrm{Ph}), 127.8(\mathrm{Ph}), 127.7(\mathrm{Ph}), 127.7(\mathrm{Ph}), 127.6(\mathrm{Ph}), 127.6(\mathrm{Ph}), 127.4(\mathrm{Ph}), 100.1\left(\mathrm{~d}, J_{\mathrm{C}-\mathrm{P}}=3.6\right.$ $\left.\mathrm{Hz}, \mathrm{C} 1, \mathrm{C} 1^{\prime}\right), 83.7\left(\mathrm{t}, J_{\mathrm{C}-\mathrm{P}}=3.6 \mathrm{~Hz}, \mathrm{C} 3, \mathrm{C} 3^{\prime}\right), 78.9\left(\mathrm{t}, J_{\mathrm{C}-\mathrm{P}}=7.5 \mathrm{~Hz}, \mathrm{C} 2, \mathrm{C} 2^{\prime}\right), 77.8\left(\mathrm{C} 4, \mathrm{C} 4^{\prime}\right), 75.2\left(\mathrm{C} 5, \mathrm{C} 5^{\prime}\right)$, $75.0\left(\mathrm{OCH}_{2} \mathrm{Ph}\right), 73.5\left(\mathrm{OCH}_{2} \mathrm{Ph}\right), 70.8\left(\mathrm{OCH}_{2} \mathrm{Ph}\right), 69.2\left(\mathrm{~d}, J_{\mathrm{C}-\mathrm{P}}=8.2 \mathrm{~Hz}, \mathrm{OCH}_{2} \mathrm{Ph}\right), 69.1\left(\mathrm{~d}, J_{\mathrm{C}-\mathrm{P}}=5.4 \mathrm{~Hz}\right.$, $\left.\mathrm{OC}^{\prime} \mathrm{H}_{2} \mathrm{Ph}\right), 69.0\left(\mathrm{OCH}_{2} \mathrm{Ph}\right), 68.7\left(\mathrm{C} 6, \mathrm{C}^{\prime}\right), 68.2\left(\mathrm{~d}, J_{\mathrm{C}-\mathrm{P}}=10.3 \mathrm{~Hz}, \mathrm{OCH}_{2}\right), 68.2\left(\mathrm{~d}, J_{\mathrm{C}-\mathrm{P}}=6.0 \mathrm{~Hz}, \mathrm{OC}^{\prime} \mathrm{H}_{2}\right)$, 32.0, 30.1, 29.8, 29.7, 29.7, 29.7, 29.6, 29.5, 29.4, 29.1, 25.4, 25.3, 22.7, 14.2; ${ }^{31} \mathrm{P}-\mathrm{NMR}\left(\mathrm{CDCl}_{3}, 122 \mathrm{MHz}\right)$ : $\delta$ (ppm) $-1.55,-1.80$ (ratio 1/1.1). HR-MS (ESI): $\mathrm{C}_{57} \mathrm{H}_{75} \mathrm{NaO}_{9} \mathrm{P}[\mathrm{M}+\mathrm{Na}]^{+}$requires: 957.5041; found: 957.5038.

3.3.3. Benzyl 3,4,6-tri-O-benzyl-2-O-[(benzyl)(cholesteryl)phosphonato]- $\beta$-D-glucopyranoside [or benzyl cholesteryl ((2R,3R,4S,5R,6R)-2,4,5-tris(benzyloxy)-6-((benzyloxy)methyl)tetrahydro-2Hpyran-3-yl) phosphate] $4 \mathrm{c}$

From cholesterol $(79 \mathrm{mg})$ following general procedure, TLC monitoring using EtOAc-pentane 1:3 as eluent, flash chromatography of the crude product (1:4 EtOAc-pentane) afforded $4 \mathbf{c}$ (yield $70 \%$ ) as a white solid. $\mathrm{Rf}=0.56 .{ }^{1} \mathrm{H}-\mathrm{NMR}\left(\mathrm{CDCl}_{3}, 500 \mathrm{MHz}\right): \delta(\mathrm{ppm}) 7.35-7.00(\mathrm{~m}, 25 \mathrm{H}, \mathrm{Ph}), 5.12(\mathrm{~m}$, $1 \mathrm{H}, \mathrm{C}=\mathrm{CH}-\mathrm{Cholesterol}), 4.98-4.79\left(\mathrm{~m}, 4 \mathrm{H}, 2 \times \mathrm{CH}_{2} \mathrm{Ph}\right), 4.78-4.66\left(\mathrm{~m}, 2 \mathrm{H}, \mathrm{CH}_{2} \mathrm{Ph}\right), 4.62-4.52(\mathrm{~m}, 2 \mathrm{H}$, $\left.\mathrm{CH}_{2} \mathrm{Ph}\right), 4.47(\mathrm{~d}, J=6 \mathrm{~Hz}, 1 \mathrm{H}, \mathrm{H} 1), 4.46-4.42\left(\mathrm{~m}, 2 \mathrm{H}, \mathrm{CH}_{2} \mathrm{Ph}\right), 4.34(\mathrm{~m}, 1 \mathrm{H}, \mathrm{H} 2), 4.05(\mathrm{~m}, 1 \mathrm{H}, \mathrm{OCH}-\mathrm{Chol})$, 3.69-3.57 (m, 4H, H3, H4, H6a, H6b), 3.41 (m, 1H, H5), 2.34-2.11 (m, 2H, $\left.\mathrm{CH}_{2}-\mathrm{Chol}\right), 1.98-1.65$ (m, 5H, Chol), 1.63-1.12 (m, 12H, Chol), 1.11-0.63 (m, 21H, Chol), 0.60-0.53 (m, 3H, Chol); ${ }^{13} \mathrm{C}-\mathrm{NMR}\left(\mathrm{CDCl}_{3}\right.$, $126 \mathrm{MHz}): \delta(\mathrm{ppm}) 139.5(\mathrm{C}=\mathrm{CH}, \mathrm{Chol}), 138.4,138.1,137.9,137.1,136.4,128.6,128.4,128.3,128.2,128.1$, 128.0, 127.9, 127.8, 127.7, 127.6, 127.4, 122.7 (C=CH, Chol), $100.2\left(\mathrm{~d}, J_{\mathrm{C}-\mathrm{P}}=3.5 \mathrm{~Hz}, \mathrm{C} 1, \mathrm{C1}\right.$ ), 83.7 (d, $\left.J_{\mathrm{C}-\mathrm{P}}=3.7 \mathrm{~Hz}, \mathrm{C} 3\right), 78.9\left(\mathrm{t}, J_{\mathrm{C}-\mathrm{P}}=6.7 \mathrm{~Hz}, \mathrm{C} 2, \mathrm{C} 2^{\prime}\right), 78.6\left(\mathrm{~d}, J_{\mathrm{C}-\mathrm{P}}=6.0 \mathrm{~Hz}, \mathrm{OCH}-\mathrm{Chol}\right), 78.5\left(\mathrm{~d}, J_{\mathrm{C}-\mathrm{P}}=5.8\right.$ $\left.\mathrm{Hz}, \mathrm{OC}^{\prime} \mathrm{H}-\mathrm{Chol}\right), 77.8\left(\mathrm{C} 4, \mathrm{C} 4^{\prime}\right), 75.1\left(\mathrm{C} 5, \mathrm{C}^{\prime}\right), 75.0\left(\mathrm{OCH}_{2} \mathrm{Ph}\right), 74.9\left(\mathrm{OCH}_{2} \mathrm{Ph}\right), 73.5\left(\mathrm{OCH}_{2} \mathrm{Ph}\right), 70.8$ $\left(\mathrm{OCH}_{2} \mathrm{Ph}\right), 69.0\left(\mathrm{~d}, J_{\mathrm{C}-\mathrm{P}}=5.5 \mathrm{~Hz}, \mathrm{OCH}_{2} \mathrm{Ph}\right), 68.7\left(\mathrm{C} 6, \mathrm{C}^{\prime}\right), 56.7,56.2,49.8,42.3,39.8,39.6,36.7,36.6$, $36.3,36.2,35.8,31.9,31.8,29.4,29.3,28.3,28.1,24.3,23.9,22.9,22.6,21.0,19.3,19.2,18.8,11.9 .{ }^{31}$ P-NMR $\left(\mathrm{CDCl}_{3}, 202 \mathrm{MHz}\right): \delta$ (ppm) $-2.60,-2.98$ (ratio 1/1.3). HR-MS (ESI): $\mathrm{C}_{68} \mathrm{H}_{88} \mathrm{O}_{9} \mathrm{P}[\mathrm{M}+\mathrm{H}]^{+}$requires: 1079.6160; found: 1079.6170 .

3.3.4. Benzyl 3,4,6-tri-O-benzyl-2-O-[(benzyl)( $5 \alpha$-cholestan-3 $\beta$-yl)phosphonato]- $\beta$-D-glucopyranoside [or benzyl cholestanyl $((2 R, 3 R, 4 S, 5 R, 6 R)-2,4,5$-tris(benzyloxy)-6-((benzyloxy)methyl)tetrahydro- $2 H$ pyran-3-yl) phosphate $4 \mathbf{d}$

From $5 \alpha$-cholestan-3 $\beta$-ol (79 mg) following general procedure, TLC monitoring by TLC using EtOAc-pentane 1:3 as eluent, flash chromatography of the crude product (1:3 EtOAc-pentane) afforded 4d (yield 74\%) as a white solid. $\mathrm{Rf}=0.37 .{ }^{1} \mathrm{H}-\mathrm{NMR}\left(\mathrm{CDCl}_{3}, 500 \mathrm{MHz}\right): \delta(\mathrm{ppm}) 7.46-7.09(\mathrm{~m}, 25 \mathrm{H}, \mathrm{Ph})$, $4.97\left(\mathrm{~m}, 3 \mathrm{H}, \mathrm{CHHPh}, \mathrm{CH}_{2} \mathrm{Ph}\right), 4.92-4.74\left(\mathrm{~m}, 3 \mathrm{H}, \mathrm{CHHPh}, \mathrm{CH}_{2} \mathrm{Ph}\right), 4.70-4.61\left(\mathrm{~m}, 2 \mathrm{H}, \mathrm{CH}_{2} \mathrm{Ph}\right), 4.57-4.56$ $\left(\mathrm{m}, 2 \mathrm{H}, \mathrm{CH}_{2} \mathrm{Ph}\right), 4.54(\mathrm{~d}, J=8.3 \mathrm{~Hz}, 1 \mathrm{H}, \mathrm{H} 1), 4.45-4.40(\mathrm{~m}, 1 \mathrm{H}, \mathrm{H} 2), 4.23-4.09$ (m, 1H, OCH-Chol), 
3.81-3.66 (m, 4H, H3, H4, H6a, H6b), 3.51 (m, 1H, H5), 1.95 (m, 1H, Chol), 1.86-1.73 (m, 2H, Chol), $1.63-1.50(\mathrm{~m}, 4 \mathrm{H}, \mathrm{Chol}), 1.44(\mathrm{~d}, J=7.4 \mathrm{~Hz}, 1 \mathrm{H}, \mathrm{Chol}), 1.41-0.94(\mathrm{~m}, 20 \mathrm{H}, \mathrm{Chol}), 0.93-0.84(\mathrm{~m}, 9 \mathrm{H}, \mathrm{Chol})$, 0.82-0.70 (m, 2H, Chol), 0.69-0.60 (m, 6H, Chol), 0.55-0.39 (m, 1H, Chol); ${ }^{13} \mathrm{C}-\mathrm{NMR}\left(\mathrm{CDCl}_{3}, 126 \mathrm{MHz}\right)$ : $\delta$ (ppm) 138.4, 138.1, 137.9, 137.2, 136.5, 128.4, 128.3, 128.3, 128.3, 128.3, 128.3, 128.0, 128.0, 128.0, 127.9, $127.8,127.8,127.8,127.8,127.7,127.7,127.7,127.5,127.4,100.2\left(\mathrm{~d}, J_{\mathrm{C}-\mathrm{P}}=1.9 \mathrm{~Hz}, \mathrm{C} 1, \mathrm{C} 1^{\prime}\right), 83.7\left(\mathrm{~d}, J_{\mathrm{C}-\mathrm{P}}=\right.$ $\left.3.7 \mathrm{~Hz}, \mathrm{C} 3, \mathrm{C} 3^{\prime}\right), 78.9\left(\mathrm{~d}, J_{\mathrm{C}-\mathrm{P}}=7.2 \mathrm{~Hz}, \mathrm{C} 2\right), 78.8\left(\mathrm{~d}, J_{\mathrm{C}-\mathrm{P}}=7.0 \mathrm{~Hz}, \mathrm{C} 2^{\prime}\right), 78.6\left(\mathrm{~d}, J_{\mathrm{C}-\mathrm{P}}=6.0 \mathrm{~Hz}, \mathrm{OCH}-\mathrm{Chol}\right)$, $77.8\left(\mathrm{C} 4, \mathrm{C}^{\prime}\right), 75.1\left(\mathrm{C} 5, \mathrm{C}^{\prime}\right), 75.0\left(\mathrm{OCH}_{2} \mathrm{Ph}\right), 74.7\left(\mathrm{OCH}_{2} \mathrm{Ph}\right), 73.5\left(\mathrm{OCH}_{2} \mathrm{Ph}\right), 70.8\left(\mathrm{OCH}_{2} \mathrm{Ph}\right), 69.0(\mathrm{~d}$, $\left.J_{\mathrm{C}-\mathrm{P}}=5.4 \mathrm{~Hz}, \mathrm{OCH}_{2} \mathrm{Ph}\right), 68.7$ (C6), 56.5, 56.3, 54.0, 44.3, 42.6, 40.0, 39.6, 36.6, 36.2, 35.8, 35.6, 35.1, 32.0, 29.3, 29.1, 28.5, 28.3, 28.1, 24.2, 23.9, 22.9, 22.6, 21.2, 18.7, 12.2, 12.1. ${ }^{31} \mathrm{P}-\mathrm{NMR}\left(\mathrm{CDCl}_{3}, 122 \mathrm{MHz}\right) \delta$ (ppm) $-2.47,-2.85$ (ratio 1/1.4). HR-MS (ESI): $\mathrm{C}_{68} \mathrm{H}_{90} \mathrm{O}_{9} \mathrm{P}[\mathrm{M}+\mathrm{H}]^{+}$requires: 1081.6317; found: 1081.6309 .

3.3.5. Benzyl 3,4,6-tri-O-benzyl-2-O-[(benzyl)[(1,3,4,6-tetrabenzyl- $\beta$-D-glucopyranos-2yl)phosphonato]- $\beta$-D-glucopyranoside [or benzyl bis $((2 R, 3 R, 4 S, 5 R, 6 R)-2,4,5$-tris(benzyloxy)-6((benzyloxy)methyl)tetrahydro-2H-pyran-3-yl) phosphate] 4e

From compound $\mathbf{1}(108 \mathrm{mg})$ following general procedure, TLC monitoring using EtOAc-pentane 1:3 as eluent, flash chromatography of the crude product (1:3 EtOAc-pentane) afforded 4e (yield 53\%) as a white solid. $\mathrm{Rf}=0.36 .{ }^{1} \mathrm{H}-\mathrm{NMR}\left(\mathrm{CDCl}_{3} 500 \mathrm{MHz}\right): \delta(\mathrm{ppm}) 7.49-7.41(\mathrm{~m}, 4 \mathrm{H}, \mathrm{Ph}), 7.37-7.27(\mathrm{~m}$, $26 \mathrm{H}, \mathrm{Ph}), 7.25-7.12(\mathrm{~m}, 13 \mathrm{H}, \mathrm{Ph}), 7.07(\mathrm{~m}, 2 \mathrm{H}, \mathrm{Ph}), 5.01-4.84\left(\mathrm{~m}, 6 \mathrm{H}, 3 \times \mathrm{CH}_{2} \mathrm{Ph}\right), 4.73(\mathrm{~d}, J=10.8 \mathrm{~Hz}, 2 \mathrm{H}$, $\left.\mathrm{CH}_{2} \mathrm{Ph}\right), 4.71-4.66\left(\mathrm{~m}, 2 \mathrm{H}, \mathrm{CH}_{2} \mathrm{Ph}\right), 4.66-4.45\left(\mathrm{~m}, 8 \mathrm{H}, 4 \times \mathrm{CH}_{2} \mathrm{Ph}\right), 4.44-4.39(\mathrm{~m}, 1 \mathrm{H}, \mathrm{H} 2), 4.35(\mathrm{~m}, 1 \mathrm{H}$, $\left.\mathrm{H} 2^{\prime}\right), 4.30(\mathrm{~d}, J=6.9 \mathrm{~Hz}, 1 \mathrm{H}, \mathrm{H} 1), 4.29\left(\mathrm{~d}, J=6.9 \mathrm{~Hz}, 1 \mathrm{H}, \mathrm{H} 1^{\prime}\right), 3.68(\mathrm{~m}, 2 \mathrm{H}, \mathrm{H} 6), 3.61$ (m, 2H, H6' $)$, 3.53-3.36 (m, 4H, H4, H4' $\left.{ }^{\prime} \mathrm{H} 3, \mathrm{H} 3^{\prime}\right), 3.35-3.26$ (m, 2H, H5, H5'); ${ }^{13} \mathrm{C}-\mathrm{NMR}\left(\mathrm{CDCl}_{3}, 126 \mathrm{MHz}\right): \delta$ (ppm) 138.5, 138.2, 138.0, 137.3, 137.3, 128.4, 128.4, 128.3, 128.3, 128.3, 128.2, 128.2, 127.9, 127.9, 127.8, 127.8, $127.8,127.7,127.7,127.7,127.6,127.5,127.5,127.4,127.4,100.2\left(\mathrm{~d}, J_{\mathrm{C}-\mathrm{P}}=2.9 \mathrm{~Hz}, \mathrm{C} 1^{\prime}\right), 99.8\left(\mathrm{~d}, J_{\mathrm{C}-\mathrm{P}}=4.2\right.$ $\mathrm{Hz}, \mathrm{C} 1), 83.6\left(\mathrm{~d}, J_{\mathrm{C}-\mathrm{P}}=4.8 \mathrm{~Hz}, \mathrm{C} 3^{\prime}\right), 83.5\left(\mathrm{~d}, J_{\mathrm{C}-\mathrm{P}}=3.6 \mathrm{~Hz}, \mathrm{C} 3\right), 79.1\left(\mathrm{~d}, J_{\mathrm{C}-\mathrm{P}}=7.4 \mathrm{~Hz}, \mathrm{C} 2^{\prime}\right), 78.6\left(\mathrm{~d}, J_{\mathrm{C}-\mathrm{P}}\right.$ $=6.8 \mathrm{~Hz}, \mathrm{C} 2), 77.7\left(\mathrm{C}^{\prime}\right), 77.6(\mathrm{C} 4), 75.0(\mathrm{C} 5), 74.8\left(\mathrm{C}^{\prime}\right), 74.8\left(\mathrm{OCH}_{2} \mathrm{Ph}\right), 74.8\left(\mathrm{OCH}_{2} \mathrm{Ph}\right), 74.7\left(\mathrm{OCH}_{2} \mathrm{Ph}\right)$, $74.7\left(\mathrm{OCH}_{2} \mathrm{Ph}\right), 73.4\left(\mathrm{OCH}_{2} \mathrm{Ph}\right), 73.4\left(\mathrm{OCH}_{2} \mathrm{Ph}\right), 70.9\left(\mathrm{OCH}_{2} \mathrm{Ph}\right), 70.2\left(\mathrm{OCH}_{2} \mathrm{Ph}\right), 69.3\left(\mathrm{~d}, J_{\mathrm{C}-\mathrm{P}}=5.0 \mathrm{~Hz}\right.$, $\left.\mathrm{OCH}_{2} \mathrm{Ph}\right), 68.7\left(\mathrm{C} 6, \mathrm{C}^{\prime}\right) ;{ }^{31} \mathrm{P}-\mathrm{NMR}\left(\mathrm{CDCl}_{3}, 122 \mathrm{MHz}\right) \delta(\mathrm{ppm})-3.64$. HR-MS (ESI): $\mathrm{C}_{75} \mathrm{H}_{77} \mathrm{NaO}_{14} \mathrm{P}[\mathrm{M}$ $+\mathrm{Na}]^{+}$requires: 1255.4943 ; found: 1255.4949 .

\subsection{Procedure for the one-step Synthesis of $4 e$}

To a solution of benzyl 3,4,6-tri-O-benzyl- $\beta$-D-glucopyranoside (1) $(783 \mathrm{mg}, 1.45 \mathrm{mmol}, 2$ eq.) and benzyloxy bis(diisopropylamino)phosphine $(297 \mathrm{mg}, 0.88 \mathrm{mmol}, 1.2 \mathrm{eq}$.) in $9 \mathrm{~mL}$ of acetonitrile was added $1 \mathrm{H}$-tetrazole $(4.95 \mathrm{~mL}$ of a 0.45 solution in $\mathrm{MeCN}, 2.2 \mathrm{mmol}, 3 \mathrm{eq}$.) at rt. Then the mixture was stirred overnight at rt. After full conversion of the starting glucoside (TLC using EtOAc-pentane 1:4.5 as eluent, intermediate phosphite $\mathrm{Rf}=0.3)$, the mixture was cooled to $0{ }^{\circ} \mathrm{C}$, then $t$ - $\mathrm{BuOOH}(170 \mu \mathrm{L}$, $0.88 \mathrm{mmol}, 1.2$ eq.) dissolved in $15 \mathrm{~mL}$ of $\mathrm{DCM}$ was added and the reaction mixture was allowed to warm to rt. After $4 \mathrm{~h}$, TLC using EtOAc-pentane 1:3 as eluent indicated that the product $4 \mathbf{e}(\mathrm{Rf}=0.36)$ was formed and no starting material remained. The white solid was filtered, the organic phase was collected, concentrated and purified by silica gel chromatography, same as in previous section.

\subsection{Procedure for the Debenzylation of Phosphodiesters $4 \mathbf{a}$ and $\mathbf{4 e}$}

\subsubsection{D-Glucose-2-phosphate (G2P) 5a}

To a solution of phosphate $4 \mathbf{a}(100 \mathrm{mg}, 0.12 \mathrm{mmol})$ in $5 \mathrm{~mL}$ of EtOAc was added $10 \% \mathrm{Pd} / \mathrm{C}(60 \mathrm{mg})$. The mixture was stirred under $1 \mathrm{~atm} \mathrm{H}_{2}$ at rt. After $24 \mathrm{~h}, \mathrm{Pd} / \mathrm{C}$ was filtered with a celite layer. The organic phase was concentrated to afford G2P as a white solid, which is showing high purity as seen by NMR $(90 \%$ yield, $\alpha / \beta=5: 3) .{ }^{1} \mathrm{H}-\mathrm{NMR}\left(\mathrm{D}_{2} \mathrm{O}, 300 \mathrm{MHz}\right) \delta(\mathrm{ppm}) 5.33(\mathrm{~d}, J=3.3 \mathrm{~Hz}, 1 \mathrm{H}, \mathrm{H} 1 \alpha), 4.69(\mathrm{~d}$, $J=7.6 \mathrm{~Hz}, 0.6 \mathrm{H}, \mathrm{H} 1 \beta), 3.98-3.88$ (m, $1 \mathrm{H}, \mathrm{H} 2 \alpha), 3.86-3.59$ (m, 5.8H, $\mathrm{H} 2 \beta, \mathrm{H} 3 \alpha, \mathrm{H} 5 \alpha, \mathrm{H} 6 \alpha, \mathrm{H} 6 \beta), 3.58$ $(\mathrm{t}, J=7.7 \mathrm{~Hz}, 0.6 \mathrm{H}, \mathrm{H} 3 \beta), 3.47-3.36(\mathrm{~m}, 2.2 \mathrm{H}, \mathrm{H} 4 \alpha, \mathrm{H} 4 \beta, \mathrm{H} 5 \beta)$. NMR data were consistent with the reported [6]. 


\subsubsection{Agrocinopine D 5b}

To a solution of phosphate $4 \mathbf{e}(100 \mathrm{mg}, 0.08 \mathrm{mmol})$ in $5 \mathrm{~mL}$ of methanol was added $10 \% \mathrm{Pd} / \mathrm{C}(60$ $\mathrm{mg}$ ). The mixture was stirred under $1 \mathrm{~atm} \mathrm{H}_{2}$ at $\mathrm{rt}$ for 1 day. TLC monitoring using DCM, acetone, $\mathrm{MeOH}, \mathrm{H}_{2} \mathrm{O}$ 4:3:3:1 (vol.) shows formation of $\mathbf{5 b}(\mathrm{Rf}=0.48)$. After filtration with a celite layer, the organic phase was concentrated to afford a white solid, which was further purified by ion exchange chromatography on a DEAE-Sephadex column pre-washed with water. The column was then eluted with a $5 \%$ to $100 \%$ gradient $1 \mathrm{M}$ ammonium carbonate. Freeze-drying the resulting fractions allows to get $5 \mathbf{b}$ as a white solid in $78 \%$ yield. ${ }^{1} \mathrm{H}-\mathrm{NMR}\left(\mathrm{D}_{2} \mathrm{O}, 500 \mathrm{MHz}\right) \delta(\mathrm{ppm}) 5.39(\mathrm{~d}, J=3.6 \mathrm{~Hz}, 1 \mathrm{H}, \mathrm{H} 1 \alpha)$, $4.75(\mathrm{~d}, J=7.9 \mathrm{~Hz}, 0.5 \mathrm{H}, \mathrm{H} 1 \beta), 4.09-3.96(\mathrm{~m}, 1 \mathrm{H}, \mathrm{H} 2 \alpha), 3.93-3.60$ (m, 6H, H2 $\beta, \mathrm{H} 3 \alpha, \mathrm{H} 3 \beta, \mathrm{H} 5 \alpha, \mathrm{H} 6 \alpha$, $\mathrm{H} 6 \beta$ ), 3.51-3.43 (m, 2H, H4 $\alpha, \mathrm{H} 4 \beta, \mathrm{H} 5 \beta$ ). HR-MS (ESI) [M - H] ${ }^{-}:$421.0753; found: 421.0735. NMR data were consistent with the reported [17]. HR-MS (ESI): $\mathrm{C}_{12} \mathrm{H}_{22} \mathrm{O}_{14} \mathrm{P}[\mathrm{M}-\mathrm{H}]^{-}$requires: 421.0753; found: 421.0735 .

\section{Conclusions}

A short and flexible access to the rare glucose-2-phosphate G2P esters including agrocinopine D is proposed. It relies on the combination of the use of benzyl 3,4,6-tri-O-benzyl- $\beta$-D-glucopyranoside prepared in two steps from the commercially available tri-O-benzyl-D-glucal and the phosphoramidite coupling strategy. It is applied to short and easy accesses to G2P itself and agrocinopine D.

Supplementary Materials: The following are available online, NMR spectra for all new compounds.

Author Contributions: Conceptualization, Y.Q., L.S. and M.A., methodology, Y.Q., L.S., Q.Z., S.-Z.L. and M.A.; validation, Y.Q., L.S., Q.Z., S.-Z.L. and M.A.; formal analysis, Y.Q., L.S., Q.Z., S.-Z.L. and M.A.; investigation, Y.Q., L.S., Q.Z., S.-Z.L. and M.A.; writing-original draft preparation, Q.Z. and Y.Q.; writing-review and editing, Y.Q.; supervision, Y.Q., L.S. and M.A.; project administration, Y.Q.; funding acquisition, Y.Q. and L.S. All authors have read and agreed to the published version of the manuscript.

Funding: This research received no additional external funding.

Acknowledgments: The authors are grateful to CNRS and MESRI for financial support and to the China Scholarship Council program for a scholarship to Qiang Zhang.

Conflicts of Interest: The authors declare no conflict of interest.

\section{References}

1. Beck Von Bodman, S.; Hayman, G.T.; Farrand, S.K. Opine catabolism and conjugal transfer of the nopaline Ti plasmid pTiC58 are coordinately regulated by a single repressor. Proc. Natl. Acad. Sci. USA 1992, 89, $643-647$. [CrossRef] [PubMed]

2. Ellis, J.G.; Kerr, A.; Petit, A.; Tempe, J. Conjugal transfer of nopaline and agropine Ti-plasmids-the role of agrocinopines. Mol. Gen. Genet. 1982, 186, 269-274. [CrossRef]

3. Reader, J.S.; Ordoukhanian, P.T.; Kim, J.-G.; de Crécy-Lagard, V.; Hwang, I.; Farrand, S.; Schimmel, P. Major biocontrol of plant tumors targets tRNA synthetase. Science 2005, 309, 1533. [CrossRef] [PubMed]

4. Roberts, W.P.; Tate, M.E.; Kerr, A. Agrocin 84 is a 6-N-phosphoramidate of an adenine nucleotide analogue. Nature 1977, 265, 379-381. [CrossRef]

5. Thompson, R.J.; Hamilton, R.H.; Pootjes, C.F. Purification and characterization of agrocin 84. Antimicrob. Agents Chemother. 1979, 16, 293-296. [CrossRef]

6. El Sahili, A.; Li, S.-Z.; Lang, J.; Virus, C.; Planamente, S.; Ahmar, M.; Guimaraes, B.G.; Aumont-Nicaise, M.; Vigouroux, A.; Soulère, L.; et al. A pyranose-2-phosphate motif is responsible for both antibiotic import and quorum-sensing regulation in Agrobacterium tumefaciens. PLoS Pathog. 2015, 11, e1005071. [CrossRef]

7. Li, S.-Z.; Vigouroux, A.; Ahmar, M.; El Sahili, A.; Soulère, L.; Sago, L.; Cornu, D.; Moréra, S.; Queneau, Y. Synthesis of a non-natural glucose-2-phosphate ester able to dupe the acc system of Agrobacterium fabrum. Org. Biomol. Chem. 2019, 17, 1090-1096. [CrossRef]

8. Mikkola, S. Hydrolysis and Isomerization of Sugar Phosphates and Carbohydrate Phosphodiesters. Curr. Org. Chem. 2013, 17, 1525-1544. [CrossRef] 
9. Tagliabracci, V.S.; Heiss, C.; Karthik, C.; Contreras, C.J.; Glushka, J.; Ishihara, M.; Azadi, P.; Hurley, T.D.; DePaoli-Roach, A.A.; Roach, P.J. Phosphate incorporation during glycogen synthesis and Lafora disease. Cell Metab. 2011, 13, 274-282. [CrossRef]

10. Chikwana, V.M.; Khanna, M.; Baskaran, S.; Tagliabracci, V.S.; Contreras, C.J.; DePaoli-Roach, A.; Roach, P.J.; Hurley, T.D. Structural basis for 2 '-phosphate incorporation into glycogen by glycogen synthase. Proc. Natl. Acad. Sci. USA 2013, 110, 20976-20981. [CrossRef]

11. Young, L.E.A.; Brizzee, C.O.; Macedo, J.K.A.; Murphy, R.D.; Contreras, C.J.; DePaoli-Roach, A.A.; Roach, P.J.; Gentry, M.S.; Sun, R.C. Accurate and sensitive quantitation of glucose and glucose phosphates derived from storage carbohydrates by mass spectrometry. Carbohydr. Polym. 2020, 230, 115651. [CrossRef] [PubMed]

12. Kokesh, F.C.; Cameron, D.A.; Kakuda, Y.; Kuras, P.V. Hydrolysis of $\alpha$-D-glucopyranose 1, 2-cyclic phosphate: The effect of $\mathrm{pH}$ and temperature on the product distribution, and the position of opening of the phosphate diester ring in formation of D-glucose 2-phosphate. Carbohydr. Res. 1978, 62, 289-300. [CrossRef]

13. Kokesh, F.C.; Stephenson, R.K.; Kakuda, Y. Inibition of potato starch phosphorylase by $\alpha$-D-glucopyranose-1, 2-cyclic phosphate. Biochim. et Biophys. Acta 1977, 483, 258-262. [CrossRef]

14. Whiteside, T.; Carreira, L.; Hilal, S. Estimation of phosphate ester hydrolysis rate constants. II. Acid and general base catalyzed hydrolysis. QSAR Comb. Sci. 2007, 26, 587-595. [CrossRef]

15. Farrar, K.R. Glucose-2 phosphate: Its preparation and characterisation by hydrolysis studies. J. Chem. Soc. 1949, 3131-3135. [CrossRef]

16. Roy, B.; Depaix, A.; Périgaud, C.; Peyrottes, S. Recent trends in nucleotide synthesis. Chem. Rev. 2016, 116, 7854-7897. [CrossRef]

17. Lindberg, M.; Oscarson, S. Synthesis of D-Glucos-2-yl Sucros-2-yl Phosphate (Agrocinopin C) and bis (D-glucos-2-yl) Phosphate (Agrocinopin D). J. Carbohydr. Chem. 1993, 12, 1139-1147. [CrossRef]

18. Froehler, B.C.; Matteucci, M.D. Nucleoside h-phosphonates: Valuable intermediates in the synthesis of deoxyoligonucleotides. Tetrahedron Lett. 1986, 27, 469-472. [CrossRef]

19. Stawinski, J.; Thelin, M. Studies on the activation pathway of phosphonic acid using acyl chlorides as activators. J. Chem. Soc. Perkin Trans. 2 1990, 849-853. [CrossRef]

20. Franzkowiak, M.; Thiem, J. Synthesen von Agrocinopin A und B. Liebigs. Ann. Chem. 1987, $1065-1071$. [CrossRef]

21. Hardegger, E.; De Pascual, J. Glucoside und $\beta-1,3,4,6$-Tetraacetyl-glucose aus Triacetyl-glucosan- $\alpha<1,2>$ $\beta<1,5>$. Helv. Chim. Acta 1948, 31, 281-286. [CrossRef] [PubMed]

22. Dick, W.E., Jr. Hydrolyses of intermediate acetoxonium ions derived from D-glucose. Carbohydr. Res. 1972, 21, 255-268. [CrossRef]

23. Helferich, B.; Zirner, J. Zur Synthese von Tetraacetyl-hexosen mit freiem 2-Hydroxyl. Synthese einiger Disaccharide. Chem. Ber. 1962, 95, 2604-2611. [CrossRef]

24. Wang, T.; Nigudkar, S.S.; Yasomanee, J.P.; Rath, N.P.; Stine, K.J.; Demchenko, A.V. Glycosyl nitrates in synthesis: Streamlined access to glucopyranose building blocks differentiated at C-2. Org. Biomol. Chem. 2018, 16, 3596-3604. [CrossRef]

25. Lubineau, A.; Queneau, Y. Stereochemical variations in aqueous cycloadditions using glyco-organic substrates as a consequence of chemical manipulations on the sugar moiety. Tetrahedron 1989, 45, 6697-6712. [CrossRef]

26. Suzuki, K.; Nonaka, H.; Yamaura, M. Reductive Ring-Opening Reaction of 1, 2-O-Benzylidene and 1,2-O-p-Methoxybenzylidene- $\alpha$-D-glucopyranose Using Diisobutyl Aluminum Hydride. J. Carbohydr. Chem. 2004, 23, 253-259. [CrossRef]

27. Lecourt, T.; Herault, A.; Pearce, A.J.; Sollogoub, M.; Sinaÿ, P. Triisobutylaluminium and diisobutylaluminium hydride as molecular scalpels: The regioselective stripping of perbenzylated sugars and cyclodextrins. Chem. Eur. J. 2004, 10, 2960-2971. [CrossRef]

28. Gordon, D.M.; Danishefsky, S.J. Displacement reactions of a 1,2-anhydro- $\alpha$-D-hexopyranose: Installation of useful functionality at the anomeric carbon. Carbohydr. Res. 1990, 206, 361-366. [CrossRef] 
29. Somasundaram, D.; Balasubramanain, K.K.; Shanmugasundaram, B. Simple and mild stereoselective O-glycosidation using 1, 2-anhydrosugars under neutral conditions. Tetrahedron Lett. 2019, 60, 764-767. [CrossRef]

30. Barone, A.D.; Tang, J.-Y.; Caruthers, M.H. In situ activation of bis-dialkylaminophosphines-a new method for synthesizing deoxyoligonucleotides on polymer supports. Nucleic Acids Res. 1984, 12, 4051-4061. [CrossRef]

Sample Availability: Not available.

(C) 2020 by the authors. Licensee MDPI, Basel, Switzerland. This article is an open access article distributed under the terms and conditions of the Creative Commons Attribution (CC BY) license (http://creativecommons.org/licenses/by/4.0/). 